“C 2013 IEEE. Personal use of this material is permitted. Permission from IEEE must be obtained for all other uses, in any current or future media, including reprinting/republishing this material for advertising or promotional purposes, creating new collective works, for resale or redistribution to servers or lists, or reuse of any copyrighted component of this work in other works." 


\title{
Control of Redundancy PEM Fuel Cells in UPS Applications with Improved Performance and Durability
}

\author{
Yuedong Zhan ${ }^{1}$, Youguang $\mathrm{Guo}^{2}$, Jianguo Zhu ${ }^{2}$ \\ ${ }^{1}$ Department of Automation, Kunming University of Science and Technology, Kunming, China \\ ${ }^{2}$ School of Electrical, Mechanical and Mechatronic Systems, University of Technology Sydney, Australia \\ E-mail: ydzhan@163.com
}

\begin{abstract}
To guarantee the reliable operation of 24 hours, improve the performance and durability of a proton exchange membrane fuel cell (PEMFC) stack, and prevent it from sudden failure in an uninterruptible power system (UPS) with hybrid backup redundancy PEMFCs, battery and supercapacitor (SC) power sources, this paper conducts research in smart power management and control strategy of two PEMFCs and UPS. Firstly, based on the analysis of the major degradation mechanisms of different components of PEMFC against the operation conditions, two PEMFCs are proposed and applied to the UPS system. The experimental results show that the proposed intelligent energy management and control strategy can effectively guarantee the power sources supplied to UPS, and automatically switch the power supply between two PEMFCs.
\end{abstract}

\section{INTRODUCTION}

A proton exchange membrane fuel cell (PEMFC) is a complex electrochemical device, which consists of many components such as catalysts layers (CLs), catalyst supports, membranes, porous transport layer or gas diffusion layers (GDLs), bipolar plates, sealings, gaskets, and so on. Each of these components can degrade or fail to function, thus causing the fuel cell system to degrade or fail [1][2].

For the CLs' degradation, according to experimental results, the degradation of CLs during long-term operation includes the carbon corrosion for a typical $\mathrm{Pt} / \mathrm{C}$ catalysis and catalyst support degradation, such as the cracking or delamination of the layer [3], catalyst ripening [4], Pt catalyst particle migration [5], the platinum catalyst degradation of $\mathrm{Pt}$ agglomeration/dissolution and particle growth [6], and $\mathrm{Pt}$ catalyst contamination [7]. For the membrane degradation, according to numerous experimental results, there are chemical degradation [8], mechanical degradation [9] and thermal degradation [10], which are strongly dependent on operating conditions such as temperature, humidity, freezethaw cycling, transient operation, and start-up/shut-down [2]. For the GDL degradation, to date, only a limited number of studies have focused on the degradation mechanisms of GDL or on the relationship between GDL properties and PEMFC performance decay, but its degradation includes the physical degradation [11], so called the mechanical and thermal degradation, and chemical and electrochemical degradation [12]. Moreover, these studies have employed mainly ex-situ GDL aging procedures in order to avoid the possible confounding effects from adjoining components such as the catalyst layer and bipolar plate. For the bipolar plate degradation mechanisms, a lot of research and some literature reviews related to bipolar plate studies have been published, such as the degradation of the graphite composite bipolar plate [13] and metal bipolar plate [14]. For the degradation of other components, there are the sealings, endplates, and bus plates [15].

Factors that affect the performance and durability include the design and assembly of fuel cell, material degradation, impurities or contaminants, and operational conditions, such as temperature, relative humidity, pressure, fuel starvation, load changing, start-up and shut-down cycling, potential cycling, freezing or thawing and so on.

According to the 2015 US Department of Energy (DOE) lifetime requirements for transportation and stationary applications, there are three top issues/berries: durability $(5000 \mathrm{~h}$ for cars, $20,000 \mathrm{~h}$ for buses, and $40,000 \mathrm{~h}$ for stationary, and degradation rate of $2-10 \mu \mathrm{V} / \mathrm{h})$, cost $(\$ 30 / \mathrm{kW})$ and efficiency (60\%). However, the three top issues or significant barriers to PEMFC commercialization in 2011 were the durability $(2,500 \mathrm{~h}$ for cars, $12,000 \mathrm{~h}$ for buses, and $10,000 \mathrm{~h}$ for stationary, and degradation rate of $15-30 \mu \mathrm{V} / \mathrm{h}$ ), cost $(\$ 49 / \mathrm{kW})$, and efficiency (53-59\%) [16].

For uninterruptible power supply (UPS) systems, PEMFCs play a very important role as the backup and emergency power supply for important applications, particularly for computers, medical/life support systems, communication systems, office equipment, hospital instruments, industrial controls and integrated data center to supply uninterruptible and reliable constant voltage and constant frequency power in case of power failure.

In order to ensure a UPS system reliability, prevent the PEMFC stack from degradation and improve its performance, based on the dynamic model of the PEMFC and description of the redundancy PEMFCs in Section 2, this paper conducts research work in intelligent energy/power management and control strategies for two redundancy PEMFCs in Section 3, such as the stack temperature, the pressures and mass flow rates of the hydrogen and air, the power tracking of load for PEMFCs or UPS, and the power supply switching between the two stacks and battery/SC. Finally, the experimental results in Section 4 show that with the proposed redundancy control strategies, not only has the degradation of fuel cell been prevented, but also the performance of PEMFC has been 
improved and the operating reliability of UPS system has been enhanced.

\section{DESCRIPTION AND MODELING OF REDUNDANCY PEMFCS}

\section{A. Description of PEMFC Generating Systems}

Aiming to guarantee the power sources for UPS, improve the reliability and the overall PEMFC performance, prevent degradation of PEMFC membrane, realize appropriate water management and balance, and prevent hydrogen and air starvation of electrochemical reaction and the leak of the membrane, an intelligent energy management and control and monitor system is designed, as shown in Figs. 1 and 2.

Fig. 1 shows the schematic diagram of the UPS system, including two $300 \mathrm{~W}$ self-humidified, air-cooling and air breathing PEMFC stacks, 3-cell lead-acid batteries in series, 20-cell supercapacitors (SCs) in series, a single phase high frequency UPS, and the intelligent energy management and control system. In Fig. 1, the auxiliary PEMFC, and battery/SC are connected to the DC bus directly. According to the load and the measurement values of current $\left(I_{1}, I_{2}, I_{3}, I_{4}\right.$ and $\left.I\right)$ and voltage $\left(V_{1}, V_{2}\right.$ and $\left.V\right)$ for the main and auxiliary PEMFCs, batteries and SCs, the intelligent energy management and control strategy can control the turning on and off of the power switches $\mathrm{K} 1-\mathrm{K} 4$ according to the desired energy and power of UPS loads, and determine the required power sources for UPS system. Fig. 2 indicates that the proposed intelligent energy management control system contains an intelligent monitoring system and five control subsystems: power tracking controller, hydrogen pressure controller, hydrogen mass flow control (HMFC), air supply and thermal controller, and power switching controller. K1 and $\mathrm{K} 2$ are two silicon-controlled rectifiers, which are used to switch the power sources between the PEMFC and battery for UPS at the sharp load changing, start-stop cycling, feed starvation, or the utility grid power failure.

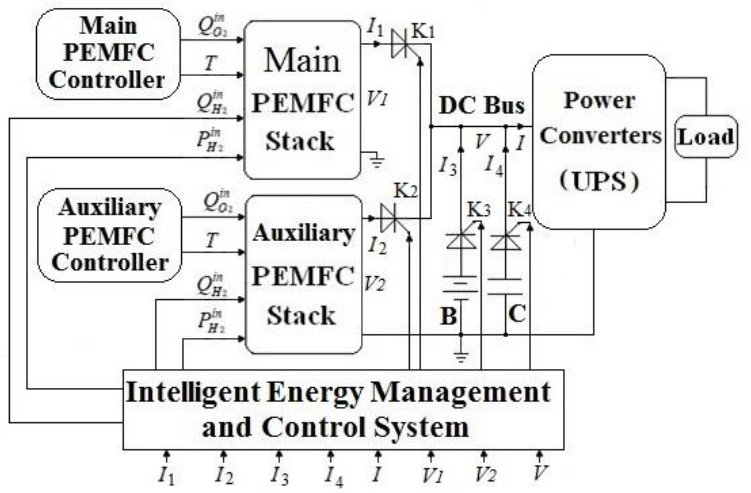

Fig. 1. Configuration of UPS system with two redundancy PEMFCs.

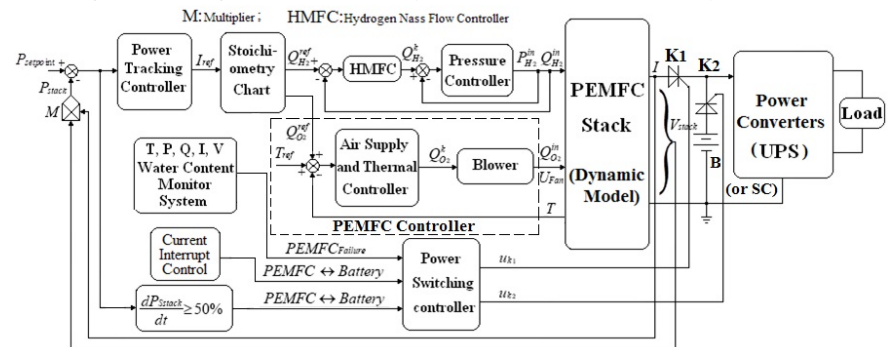

Fig. 2. Configuration of intelligent energy management and control system for two PEMFCs, battery and SC.

\section{B. Voltage Modeling of PEMFCs}

Because the PEMFC is a type of electrochemical energy conversion device, if the parameters for each single cell are lumped to represent the stack, the output voltage of the stack can be obtained as

$$
\begin{aligned}
V_{\text {stack }} & =E_{\text {reversible }}-V_{\text {actLOSS }}-V_{\text {OhmicLOSS }}-V_{\text {concLOSs }}-V_{\text {leakLOSS }} \\
& =E_{\text {reversible }}-N\left\{\frac{R T_{S}}{\alpha n F} \ln \left(\frac{i+i_{n}}{i_{0}}\right)+R_{\text {Ohmic }}\left(i+i_{n}\right)+\frac{R T_{S}}{n F} \ln \left[\frac{i_{L}}{i_{L}-\left(i+i_{n}\right)}\right]\right\}
\end{aligned}
$$

where $V_{\text {actLoss }}$ is the activation voltage loss (V); V VhmicLOSS Ohmic voltage loss $(\mathrm{V})$; $V_{\text {concLoss }}$ concentration voltage loss (V); VleakLoss leakage voltage loss (due to internal current) (V); $E_{\text {reversible }}$ the reversible voltage $(\mathrm{V}) ; N$ the number of cells in a PEMFC stack; $\alpha$ the transfer coefficient; $n$ the number of electrons per molecule of $\mathrm{H}_{2}$ (2 electrons per molecule); $R$ the universal gas constant $(\mathrm{J} / \mathrm{mol} \cdot \mathrm{K}) ; T_{S}$ the stack temperature $(\mathrm{K}) ; \quad F$ the Faraday's constant $(\mathrm{C} / \mathrm{mol}) ; R_{\text {Ohmic }}$ the areanormalized resistance, also known as area specific resistance (ARS) of the PEMFC measured $\left(\Omega \cdot \mathrm{cm}^{2}\right) ; i_{0}$ the exchange current density $\left(\mathrm{A} / \mathrm{cm}^{2}\right) ; i_{L}$ the limiting current density at which the cell voltage will fall rapidly $\left(\mathrm{A} / \mathrm{cm}^{2}\right) ; i_{n}$ the internal current or parasitic current density that is wasted $\left(\mathrm{A} / \mathrm{cm}^{2}\right)$; and $i$ the PEMFC stack current density $\left(\mathrm{A} / \mathrm{cm}^{2}\right)$.

The reversible voltage at varying temperatures and pressures can be expressed as

$$
E_{\text {reversible }}=N\left\{E^{0}+\frac{R T_{S}}{2 F} \ln \left[\frac{P_{\mathrm{H}_{2}}\left(P_{\mathrm{O}_{2}}\right)^{\frac{1}{2}}}{P_{\mathrm{H}_{2} \mathrm{O}}}\right]+\frac{\Delta \bar{s}_{298.15 K}}{2 F}\left(T_{S}-298.15\right)\right\}
$$

where $P_{i}$ is the partial pressure of species $i\left(i\right.$ is $\mathrm{H}_{2}, \mathrm{O}_{2} /$ air, or liquid water at cathode side) $(\mathrm{kPa})$, respectively; $E^{0}$ the cell open-circuit voltage (OCV) at the Standard Temperature and Pressure (STP); and $\Delta \bar{s}_{298.15 K}$ the change in the molar entropy at $\operatorname{STP}(\mathrm{J} / \mathrm{mol} \cdot \mathrm{K})$.

According to the ideal gas law and the mole conservation rule, a detailed dynamic model of the PEMFC is shown in Fig. 3. This model is based on the relationship between output voltage and current and the partial pressures of hydrogen, oxygen/air and produced water, temperature and mass flow rates of the stacks as in [17].

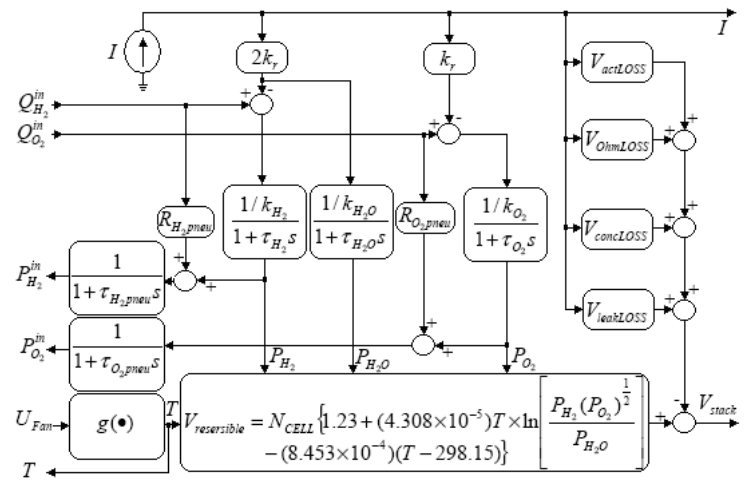

Fig. 3. PEMFC dynamic model. 


\section{INTELLIGENT ENERGY MANAGEMENT AND CONTROL STRATEGY FOR TWO PEMFCS}

\section{A. Power Tracking Controller}

According to the real-time current and voltage measurements of PEMFC stack, the power (ranging from 12 to $330 \mathrm{~W}$ ) can be firstly calculated. The output power $P_{\text {stack }}$ and energy $E_{\text {stack }}$ of the fuel cell stack can be calculated by

$$
P_{\text {stack }}=V_{\text {stack }} I, \quad E_{\text {stack }}=P_{\text {stack }} t
$$

Based on the load at that time, a power tracking controller is designed to continuously distribute the current or real-time power by using the setup value of the reference mass flow $Q_{H_{2}}^{r e f}$ and $Q_{O_{2}}^{r e f}$ of hydrogen and air and according to the stoichiometry ratios of PEMFC. The mass flow rates of hydrogen and air for the stack can be calculated as follows.

$$
\begin{gathered}
Q_{H_{2}}^{r e f}=22.4 \times 60 \times \frac{I N}{2 F} \times S_{H_{2}} \\
Q_{O_{2}}^{r e f}=22.4 \times 60 \times \frac{M_{A i r} I N}{4 F} \times S_{O_{2}}
\end{gathered}
$$

where $S_{H_{2}}$ is the stoichiometry ratio of hydrogen, which is selected within 1.2 1.5. $M_{\text {Air }}$ is the air mass $(\mathrm{kg})$ and $S_{\mathrm{O}_{2}}$ is the required stoichiometric ratio, which is selected within $20 \sim 30$.

\section{B. Hydrogen Pressure Controller}

The PID control is used in the pressure controller, so the hydrogen output controlling variable is

$$
Q_{H_{2}}^{k}=K_{P} e_{H_{2}}(k T)+\frac{T}{T_{I}} \sum_{j}^{k} e(j T)+\frac{T_{D}}{T}\left[e_{H_{2}}(k T)-e_{H_{2}}(k T-T)\right]
$$

where $e_{H_{2}}(k T)=P_{H_{2}}^{r e f}(k T)-P_{H_{2}}^{i n}(k T)$ and $\mathrm{T}$ is the sampling period (ms).

\section{Hydrogen Mass Flow Controller}

The fuzzy-PI controller input variables are the mass flow error $e(k)$, and the change of error $c(k)$ of hydrogen. The output variables of the controller are the optimal $P$ and $I$ gains of a subsequent PI controller device, one of them gives the proportional part $K$ as a function of $e(k)$ and $c(k)$, and the other gives the increment $\Delta T$. There are seven fuzzy subsets: positive big (PB), positive medium (PM), positive small (PS), zero (ZE), negative small (NS), negative medium (NM), and negative big (NB), which have been selected for the input and output variables $e(k), c(k), K$ and $T$.

The selected control rules are described as follows.

1) Far from the mass flow set point:

If $\mathrm{e}(\mathrm{k})$ is $\mathrm{PB}$, then $K$ is $\mathrm{PB}$ and $T$ is $\mathrm{ZE}$;

If $\mathrm{e}(\mathrm{k})$ is $\mathrm{NB}$, then $K$ is $\mathrm{NB}$ and $T$ is $\mathrm{ZE}$.

2) Close to the mass flow set point:

If both $\mathrm{e}(\mathrm{k})$ and $\mathrm{c}(\mathrm{k})$ are $\mathrm{ZE}$, then $K$ and $T$ are $\mathrm{ZE}$;

If both $\mathrm{e}(\mathrm{k})$ and $\mathrm{c}(\mathrm{k})$ are negative, then $K$ and $T$ are negative;

If both e(k) and c(k) are positive, then $K$ and $T$ are positive.

\section{Air Supply and Thermal Controller}

The PEMFC belongs to the low temperature stack $(<100$ ${ }^{\circ} \mathrm{C}$ ) in the fuel cell family, but its operating temperature is still higher than the ambient temperature and should be maintained within an appropriate range. In this paper, the best operating temperature of the PEMFC is at $50 \sim 55^{\circ} \mathrm{C}$ (the maximum stack temperature is $65^{\circ} \mathrm{C}$ ) according to the operating temperature demands.

The air supplying and cooling control rules are: (rpm=revolutions per minutes)

If $T_{\text {stack }}$ is less than $50^{\circ} \mathrm{C}$, then

$$
Q_{O_{2}}^{k}=K_{P} e(t)+T \int e(t) d t(r p m) ;
$$

If $T_{\text {stack }}$ is between $50{ }^{\circ} \mathrm{C}$ and $60^{\circ} \mathrm{C}$, then

$Q_{\mathrm{O}_{2}}^{k}=$ Adaptive varying-speed control strategy (rpm);

If $P_{\text {stack }}$ is over $330 \mathrm{~W}$ or $T_{\text {stack }}$ is over $60^{\circ} \mathrm{C}$, then the PEMFC is shut down.

\section{E. Power Switching Controller}

To avoid the hydrogen and air starvation, in this paper, a power switching controller is designed, which can control the power source of UPS to switch between PEMFC and battery according to the change rate of the power of the PEMFC stack. Transient issues associated with temporary hydrogen and air starvation can be avoided by supplying the power from the battery and slowing down the current drawn from the PEMFC through a change rate limiter of the power output.

To realize the operation as mentioned above, the intelligent control rules are as follows. As shown in Fig. $2, u_{k_{1}}=1$ means that the $\mathrm{K} 1$ turns on; $u_{k_{1}}=0$ means that the $\mathrm{K} 1$ turns off; $u_{k_{2}}=0$ means that K2 turns off; $u_{k_{2}}=1$ means that the $\mathrm{K} 2$ turns on.

If the $\frac{d P_{\text {stack }}}{d t} \geq 50 \%$, then $u_{k_{2}}=0$ and $u_{k_{3}}=1$;

If the PEMFC fails, then $u_{k_{1}}=0$ and $u_{k_{2}}=1$.

\section{F. Intelligent Energy Management and Control Strategy}

When one of the PEMFCs fails, the other can be turned on using the switches $\mathrm{K} 1$ and $\mathrm{K} 2$ through the intelligent energy management and control system, as shown in Fig. 1. The intelligent control rules are

If PEMFC1 fails, then K1, and K3 or K4 turn off;

If PEMFC2 fails, then K2, and K3 or K4 turn off;

If both PEMFC1 and PEMFC2 fail, then K1 and K2 turn off, and $\mathrm{K} 3$ or K4 turns on.

\section{EXPERIMENTAL RESULTS}

Experimental study has been conducted on the designed UPS with the backup PEMFCs, battery and SC. The proposed intelligent power management and control strategies have been implemented in the two PEMFC generating systems. Based on the control methods, the output voltage and current of the two PEMFC stacks can be easily controlled according to the PEMFC operating status in the UPS, as shown in Fig. 4. If PEMFC1 fails, the intelligent energy management and 
control system could seamlessly switch the power source supplied UPS from PEMFC1 to PEMFC2.

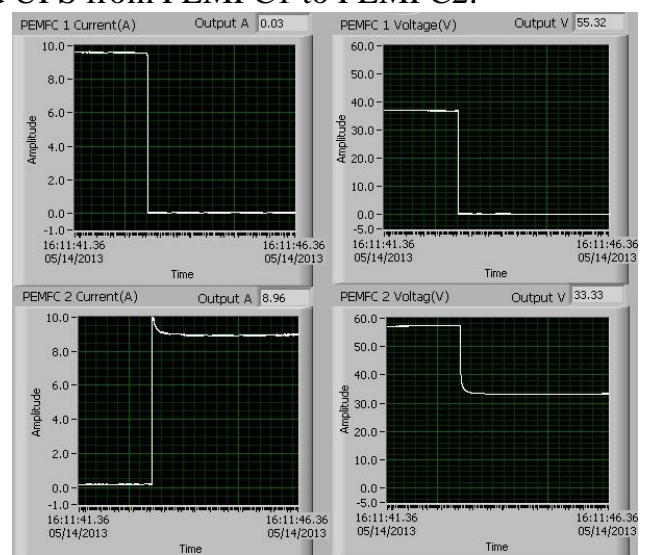

Fig. 4. Current and voltage waveforms of two PEMFCs when PEMFC1 fails.

Fig. 5 shows the control performance of two PEMFCs in parallel. When the intelligent energy management and control system turns on both the switches $\mathrm{K} 1$ and $\mathrm{K} 2$, an auxiliary PEMFC is used to work together with the main PEMFC in parallel, which indicates that two PEMFCs supply the reliable power sources for UPS system.

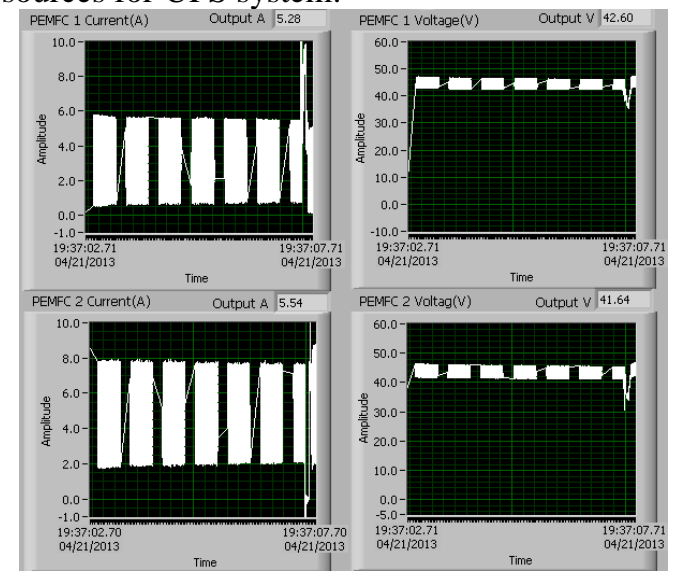

Fig. 5. Voltages and currents of main and auxiliary PEMFCs supplied UPS system with power sources in parallel.

Performances of the intelligent energy/power management and control and the conventional PI control (hydrogen mass flow rate) of two stacks are given in Fig. 6 .

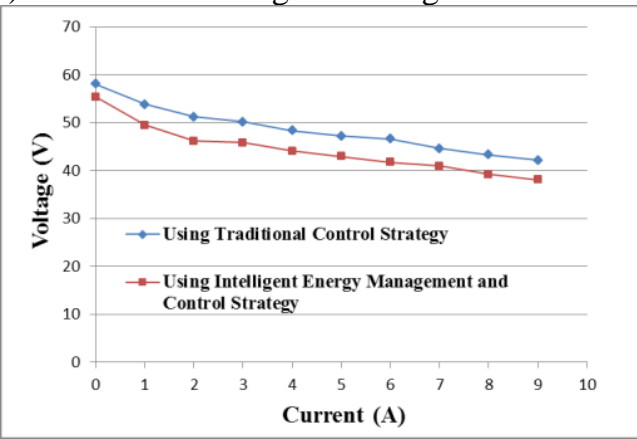

Fig. 6. PEMFC performance comparison between intelligent power management and control and conventional PI control.

\section{CONCLUSION}

This paper presents the intelligent energy management and control of two redundancy PEMFCs for a UPS system to enhance the reliability and improve the performance and durability. Based on the description and voltage modelling of
PEMFCs, the intelligent energy management and control strategy for two PEMFC generating systems in UPS applications is conducted and obtained experimentally, which are the operating performance of the main and auxiliary PEMFCs in parallel. Experimental results indicate that the developed strategy with UPS hybrid PEMFC/battery/SC power sources is suitable for the reliable operation of 24 hours.

\section{REFERENCES}

[1] H. J. Wang, H. Li, and X. Yuan, PEM Fuel Cell Failure Mode Analysis, CRC Press, 2012.

[2] W. Schmittinger and A. Vahidi, "A review of the main parameters influencing long-term performance and durability of PEM fuel cells," Journal of Power Sources, Vol. 180, No. 1, pp. 1-14, May 2008.

[3] H. Meng, "Numerical analyses of non-isothermal self-start behaviors of PEM fuel cells from subfreezing startup temperatures," International Journal of Hydrogen Energy, Vol. 33, No. 20, pp. 5738-5747, October 2008.

[4] Y. C. Park, K. Kakinuma, M. Uchida, D. A. Tryk, T. Kamino, H. Uchida, and M. Watanab, "Investigation of the corrosion of carbon supports in polymer electrolyte fuel cells using simulated startup/shutdown cycling," Electrochimica Acta, Vol. 91, pp. 195-207, February 2013.

[5] S. C. Mu, P. Zhao, C.. Xu, and Y. Gao, "Detaching behaviors of catalyst layers applied in PEM fuel cells by off-line accelerated test," International Journal of Hydrogen Energy, Vol. 35, No. 15, pp. 81558160, August 2010.

[6] E. S. Şayin, A. Bayrakçeken, and I. Eroğlu, "Durability of PEM fuel cell electrocatalysts prepared by microwave irradiation technique," International Journal of Hydrogen Energy, Vol. 37, No. 21, pp. 1666316672, November, 2012.

[7] L. Franck-Lacaze, C. Bonnet, S. Besse, and F. Lapicque, "Effects of ozone on the performance of a polymer electrolyte membrane fuel cell," Fuel Cells, Vol. 9, No. 5, pp. 562-569, October 2009.

[8] S. Hommura, K. Kawahara, T. Shimohira, and Y. Teraoka, "Development of a method for clarifying the perfluorosulfonated membrane degradation mechanism in a fuel cell environment," Journal of the Electrochemical Society, Vol. 155, No. 1, pp. A29-A33, 2008.

[9] M. B. Satterfield, P. W. Majsztrik, H. Ota, J. B. Benziger, and A. B. Bocarsly, "Mechanical properties of Nafion and titania/Nafion composite membranes for polymer electrolyte membrane fuel cells," Journal of Polymer Science Part B: Polymer Physics, Vol. 44, No. 16, pp. 2327-2345, August 2006.

[10] A. Taniguchi, T. Akita, K. Yasuda, and Y. Miyazaki, "Analysis of degradation in PEMFC caused by cell reversal during air starvation," International Journal of Hydrogen Energy, Vol. 33, No. 9, pp. 23232329, May 2008.

[11] C. Lee, and W. Merida, "Gas diffusion layer durability under steadystate and freezing conditions," Journal of Power Sources, Vol. 164, No. 1, pp. 141-153, January 2007.

[12] D. L. Wood, C. Rulison, and R. L. Borup, "Surface properties of PEMFC gas diffusion layers," Journal of the Electrochemical Society, Vol. 157, No. 2, pp. B195-B206, 2010.

[13] C. Hartnig, and T. J. Schmidt, "On a new degradation mode for hightemperature polymer electrolyte fuel cells: How bipolar plate degradation affects cell performance," Electrochimica Acta, Vol. 56, No. 11, pp. 4237-4242, April 2011.

[14] L. J. Yang, H. J. Yu, L. J. Jiang, L. Zhu, X. Y. Jian,and Z. Wang, "Improved anticorrosion properties and electrical conductivity of $316 \mathrm{~L}$ stainless steel as bipolar plate for proton exchange membrane fuel cell by lower temperature chromizing treatment," Journal of Power Sources, Vol. 195, No. 9, pp. 2810-2814, May 2010.

[15] H. N. Yu, S. S. Kim, J. D. Suh, and D. G. Lee, "Axiomatic design of the sandwich composite endplate for PEMFC in fuel cell vehicles," Composite Structures, Vol. 92, No. 6, pp. 1504-1511, May 2010.

[16] 2011 Technical Plan - FCs of U.S. Department of Energy, [online], http://www1.eere.energy.gov/hydrogenandfuelcells/mypp/pdfs/fuel_cell s.pdf

[17] Y. D. Zhan, H. Wang, and J. G. Zhu, "Modelling and control of hybrid UPS system with backup PEM fuel cell/battery," International Journal of Electrical Power \& Energy Systems, Vol. 43, No. 1, pp. 1322-1331, December 2012. 